\title{
Non-Communicable Disease (NCD) Profile in Workers of a Private Iron Ore Mine in Jharkhand: A Cross-Sectional Study
}

\author{
Amala Sankar Chatterjee \\ Sr. Registrar \& Doctor-in-Charge, Occupational Health, Tata Steel Hospital, Noamundi-833217, \\ West Singhbhum, Jharkhand, India. \\ DOI: https://doi.org/10.24321/2394.6539.201802
}

\begin{abstract}
Introduction: Non-Communicable Diseases (NCDs) are assuming increasing importance among the adult population worldwide and one of the major emerging health problems affecting both males and females. Over the last few years, India is experiencing a rising burden of NCDs, which mainly includes: cardiovascular diseases, stroke, diabetes, cancer, MSD, chronic respiratory diseases, accidents and injuries and mental health.

Methods: A cross-sectional study was conducted to find the epidemiological profile and prevalence of NCDs among 140 workers in a private Iron Ore Mine in Jharkhand.

Results: The study revealed, most of the employees (47\%) were pre-obese or obese with a Body Mass Index (BMI)> 25. 41\% of the workers were smoker, 31\% alcoholic. Musculoskeletal Disorders (MSD), Hypertension and Diabetes found in $23 \%, 19 \%$ and $14 \%$ respectively. BMI was significantly associated (at $p<0.05)$ with hypertension $\left(x^{2}=5.1171, p=0.023691\right)$ and diabetes $\left(x^{2}=4.8922, p=0.026979\right)$. Smoking also showed statistically significant association $\left(x^{2}=6.86, p=0.008815, p<0.05\right)$ with hypertension.

Conclusions: NCDs were common among the mining workers. The study emphasized the need of communitybased wellness program along with some specific recommendations to prevent NCDs among the mining workers.
\end{abstract}

Keywords: BMI, Diabetes, Hypertension, MSD, NCD

\section{Introduction}

"Occupational Health" is the promotion and maintenance of highest degree of physical, mental and social well-being of workers in all occupations. ${ }^{1}$

Non-Communicable Diseases (NCDs) are assuming increasing importance among the adult population worldwide and it is one of the major emerging health problems affecting both males and females. ${ }^{2}$ Due to increased urbanization and industrialization, socio-economic development, changing lifestyles, non-communicable diseases are posing major health problem globally.

Over the last few years, India is experiencing a rising burden of NCDs- which are an important public health problem.

Traditionally, agriculture is the backbone of Indian economy. But in recent years there is more urbanization and industrialization and hence migration of labour workers also increased. With these migrations of labour workers far away from their home, the habits like alcoholism, smoking

E-mail Id: dras.chatterjee@gmail.com

Orcid Id: https://orcid.org/0000-0002-0967-9553

How to cite this article: Chatterjee AS. Non-Communicable Disease (NCD) Profile in Workers of a Private Iron Ore Mine in Jharkhand: A Cross-Sectional Study. J Adv Res Med Sci Tech 2018; 5(1): 6-13. 
and tobacco chewing is also increased due to various factors like loneliness, peer pressure etc. ${ }^{3}$ and the major causes for the increase in cases of non-communicable diseases are dyslipidaemia, overweight, obesity, physical inactivity, tobacco use, alcohol consumption, and taking unhealthy diet. ${ }^{4,5}$

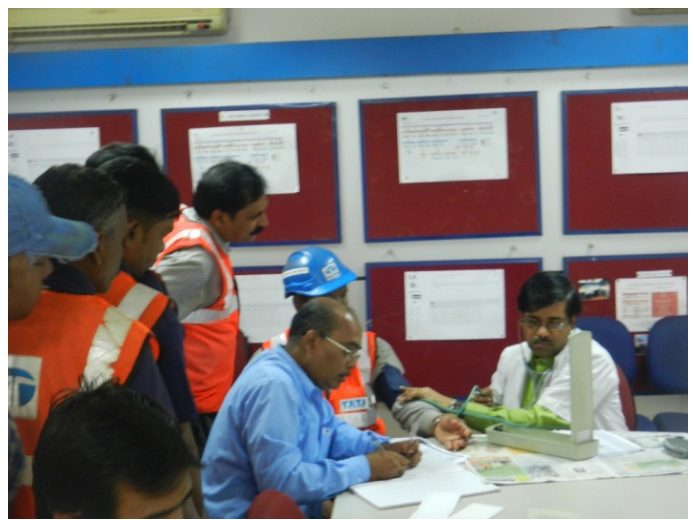

Figure 1.Employees' health check-up at shop floor NCDs refer to those conditions which are chronic evolve slowly and progress relentlessly and it mainly includes: cardiovascular diseases, stroke, diabetes mellitus, cancer, MSD, chronic respiratory diseases, accidents and injuries and mental health. ${ }^{2}$

Many of the risk factors for NCD are due to lifestyle and can be prevented. Drug treatments can be inexpensive but remain out of reach for many people. Even when affordable, care is often not organized to deal with NCDs and their risk factors. The fight against non-communicable diseases needs to start today and be the prime focus tomorrow. ${ }^{6}$

Mining is a very old occupation, being recognized as a job which has high risk of injury and disease. It is one of the most hazardous industries. Mining is a multi-disciplinary industry, drawing on several professions and trades.

Mining workers are exposed to various potentially toxic or harmful materials or agents like fuels, reagents, solvents, detergents, dusts, heat, noise, welding fumes etc. As a result, many disorders develop through the passage of time. $^{7}$

Few studies were carried out in India amongst mining workers and the factors associated with non-communicable diseases. So, this study was conducted with the objective to know the health status of mining workers, to find out the prevalence of NCDs among them and to study factors associated with it.

\section{Methodology}

A cross-sectional study was conducted through health check-up to find the spectrum, epidemiological profile and prevalence of NCDs among 140 workers in a private Iron Ore Mine in Jharkhand during April-July 2017. Data were collected by their routine health check-up as a part of regular medical examination and among them 140 workers randomly selected for the study. They were from different departments, different age groups and from both the sex.

All the workers were given general pro forma and the answers were noted. Formal consent was taken from each individual and also from the HR department. The pro forma was used to collect information on socio- demographic profile, personal habit like smoking, tobacco, alcohol consumption etc.

A thorough clinical examination was done as routine medical examination. Main focus was given on past and family history also for major factors like hypertension, diabetes mellitus, obesity, previous history of any ischemic heart disease or acute coronary syndrome, any past history of injury or accident, cancer etc.

Prevalence of non-communicable diseases were analysed based on age, duration of exposure, educational qualification, socio-economic status, present working experience, onset of symptoms, pre-existing disease or illness etc.

\section{Operational Definitions}

\section{Diabetes Mellitus (DM)}

The current WHO diagnostic criteria for diabetes should be maintained-fasting plasma glucose $\geq 7.0 \mathrm{mmol} / \mathrm{l}$ (126 $\mathrm{mg} / \mathrm{dL}$ ) or $2 \mathrm{~h}$ plasma glucose $\geq 11.1 \mathrm{mmol} / \mathrm{l}(200 \mathrm{mg} / \mathrm{dL}){ }^{8}$

Fasting and post-prandial blood sugar levels were estimated for each employee and diabetes mellitus was defined as WHO definition mentioned above and the workers who are already diagnosed cases of diabetes and taking medicines, were also included as diabetic.

\section{Hypertension (HTN)}

Estimated with Sphygmomanometer and a level of Systolic $>140 \mathrm{mmHg}$, Diastolic $>90 \mathrm{mmHg}$ was labelled as hypertension. ${ }^{9}$ As the diabetics, the workers who are already diagnosed cases of hypertension and taking antihypertensive medicines, were also included as hypertensive.

\section{Body Mass Index (BMI)}

$\mathrm{BMI}^{10}$ was calculated by considering height $(\mathrm{m})$ and weight (Kg) by using following formula. BMI = Weight $(\mathrm{Kg}) /$ Height $\left(\mathrm{m}^{2}\right)$.

\section{Statistical Analysis}

Chi-Square $\left(\mathrm{x}^{2}\right)$ test used for statistical analysis by simple online Chi-Square calculator (at $p<0.05$ ). As per the study, BMI was significantly associated (at $p<0.05$ ) 
with hypertension $\left(x^{2}=5.1171, d f=1, p=0.023691\right)$ and diabetes $\left(x^{2}=4.8922, d f=1, p=0.026979\right)$. Smoking also showed statistically significant association $\left(x^{2}=6.86, \mathrm{df}=1, p\right.$ $=0.008815, p<0.05$ ) with hypertension (Table 3B, 4B \& 5B).

\section{Results}

\section{Socio demographic Profile (Table 1)}

As per the study, mean age of employees was $43.43 \pm 9.39$ years, maximum of the workers were from the age group $41-50$ years (35\%). 94\% were male, $6 \%$ female, $89 \%$ married. Per Capita Income was maximum (41\%) among the income group with Rs. 5,001-10,000.

There were $41 \%(n=57)$ smoker whereas $31 \%(n=43)$ were alcoholic. Almost half of the workers $(n=67,48 \%)$ were miscellaneously addicted to smokeless tobacco, among them $57 \%$ were addicted to Khaini and $15 \%$ addicted to both Khaini and Gutkha, which are very dangerous for health.

Table 1.Socio demographic profile of study subjects

\begin{tabular}{|c|c|c|}
\hline Characteristics of the participants $(n=140)$ & Frequency & Percentage \\
\hline \multicolumn{3}{|c|}{ Age (Years) } \\
\hline $21-30$ & 19 & $14 \%$ \\
\hline $31-40$ & 30 & $21 \%$ \\
\hline $41-50$ & 49 & $35 \%$ \\
\hline $51-60$ & 42 & $30 \%$ \\
\hline \multicolumn{3}{|c|}{ Working experience in current job (years) } \\
\hline $5 \leq$ & 33 & $24 \%$ \\
\hline $6-15$ & 23 & $16 \%$ \\
\hline $16-25$ & 46 & $33 \%$ \\
\hline$\geq 25$ & 38 & $27 \%$ \\
\hline \multicolumn{3}{|c|}{ Educational qualification } \\
\hline Graduate and above & 38 & $27 \%$ \\
\hline Higher secondary and diploma & 30 & $21 \%$ \\
\hline Matriculation & 47 & $34 \%$ \\
\hline Below matriculation (Up to class IX) & 25 & $18 \%$ \\
\hline \multicolumn{3}{|c|}{ Marital status } \\
\hline Married & 124 & $89 \%$ \\
\hline Unmarried & 16 & $11 \%$ \\
\hline \multicolumn{3}{|c|}{ Per capita income (Rs.) } \\
\hline$\leq 5,000$ & 30 & $21 \%$ \\
\hline $5,001-10,000$ & 57 & $41 \%$ \\
\hline $10,001-15,000$ & 48 & $34 \%$ \\
\hline$>15,000$ & 05 & $04 \%$ \\
\hline \multicolumn{3}{|c|}{ Personal habit (Smoking) } \\
\hline Smoker & 57 & $41 \%$ \\
\hline Non- Smoker & 83 & $59 \%$ \\
\hline \multicolumn{3}{|c|}{ Habit of addiction to smokeless tobacco $(n=67) *$} \\
\hline Khaini & 38 & $57 \%$ \\
\hline Gutkha & 19 & $28 \%$ \\
\hline Both (Khaini and Gutkha) & 10 & $15 \%$ \\
\hline \multicolumn{3}{|c|}{ Personal habit (Alcohol consumption) } \\
\hline Alcoholic & 43 & $31 \%$ \\
\hline Non-alcoholic & 97 & $69 \%$ \\
\hline
\end{tabular}


Non-Communicable Disease (NCD) with Risk Profile (Table 2)

Study revealed that, $19 \%$ of the workers were hypertensive and $14 \%$ were diabetic. $53 \%$ of the workers had normal BMI (18.5-24.9), whereas almost half of the workers (47\%) have high BMI ( $\geq 25$ ) among which $41 \%$ overweight and $6 \%$ obese. No person was in underweight group. $23 \%$ of the workers were suffering from MSD and most of them were abobe 40 years ( $84 \%$ ) with working experience more than 20 years.

$4 \%(n=05)$ workers were suffering from IHD. Most of them were in age group of $41-50$ and $51-60$ years (40\% each). Chronic respiratory disease (COPD, asthma) were seen among $2 \%(n=03)$ workers, all of them were above 45 years. Refractive error (cataract) were seenamong $2 \%$ $(n=03)$ workers and all of them were above 50 years. There was a single case (follow-up) of Carcinoma Right Lung (adenocarcinoma) under treatment.

Table 2.Subjects suffering from non-communicable disease and risk profile

\begin{tabular}{|c|c|c|}
\hline Non-communicable disease profile & Frequency & Percentage \\
\hline \multicolumn{3}{|c|}{ Hypertension } \\
\hline Hypertensive & 27 & $19 \%$ \\
\hline Normotensive & 113 & $81 \%$ \\
\hline \multicolumn{3}{|c|}{ Hypertension-age wise distribution $(n=27)$} \\
\hline $21-30$ & 00 & $00 \%$ \\
\hline $31-40$ & 02 & $07 \%$ \\
\hline $41-50$ & 10 & $37 \%$ \\
\hline $51-60$ & 15 & $56 \%$ \\
\hline \multicolumn{3}{|c|}{ Diabetes mellitus } \\
\hline Diabetic & 20 & $14 \%$ \\
\hline Non-Diabetic & 120 & $86 \%$ \\
\hline \multicolumn{3}{|c|}{ Diabetes mellitus - age wise distribution $(n=20)$} \\
\hline $21-30$ & 00 & $00 \%$ \\
\hline $31-40$ & 02 & $10 \%$ \\
\hline $41-50$ & 07 & $35 \%$ \\
\hline $51-60$ & 11 & $55 \%$ \\
\hline \multicolumn{3}{|c|}{ BMI } \\
\hline 18.5-24.9 (Normal) & 74 & $53 \%$ \\
\hline 25.0-29.9 (Overweight) & 58 & $41 \%$ \\
\hline$\geq 30$ (Obese) & 08 & $06 \%$ \\
\hline \multicolumn{3}{|c|}{ High BMI - age wise distribution $(n=66)$} \\
\hline $21-30$ & 04 & $06 \%$ \\
\hline $31-40$ & 13 & $20 \%$ \\
\hline $41-50$ & 26 & $39 \%$ \\
\hline $51-60$ & 23 & $35 \%$ \\
\hline
\end{tabular}




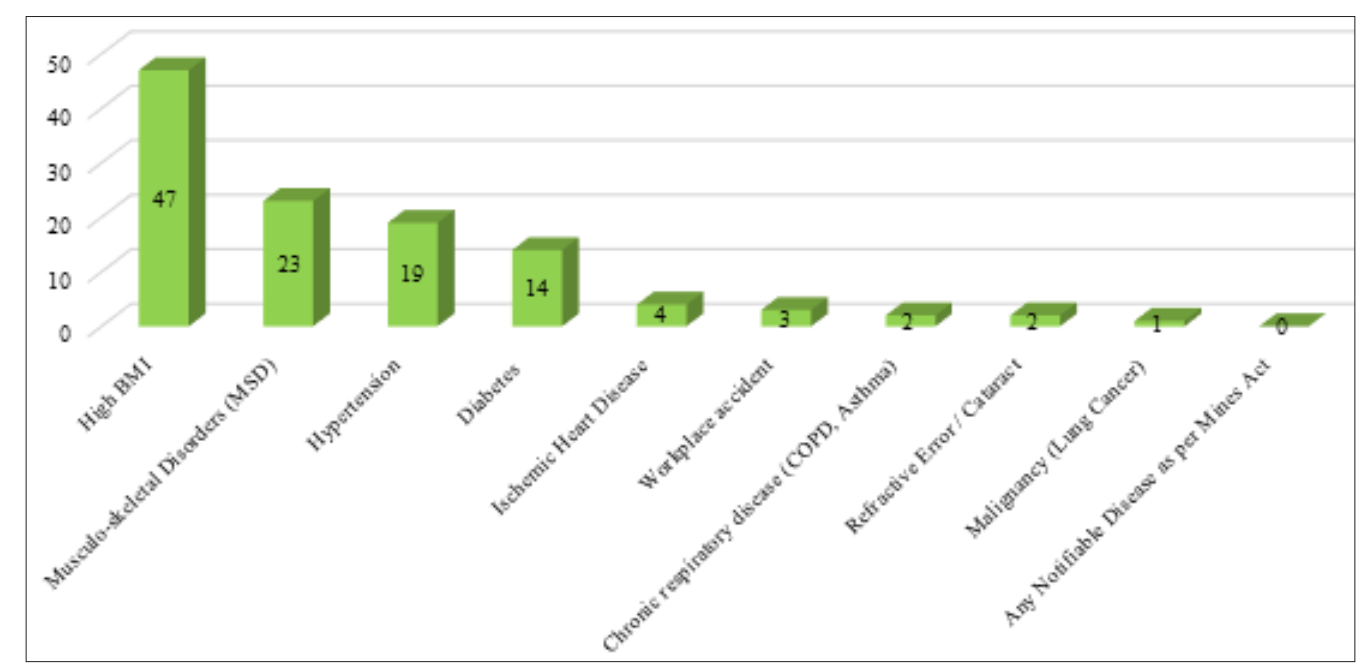

Figure 2.Distribution of workers according to study findings (\%)

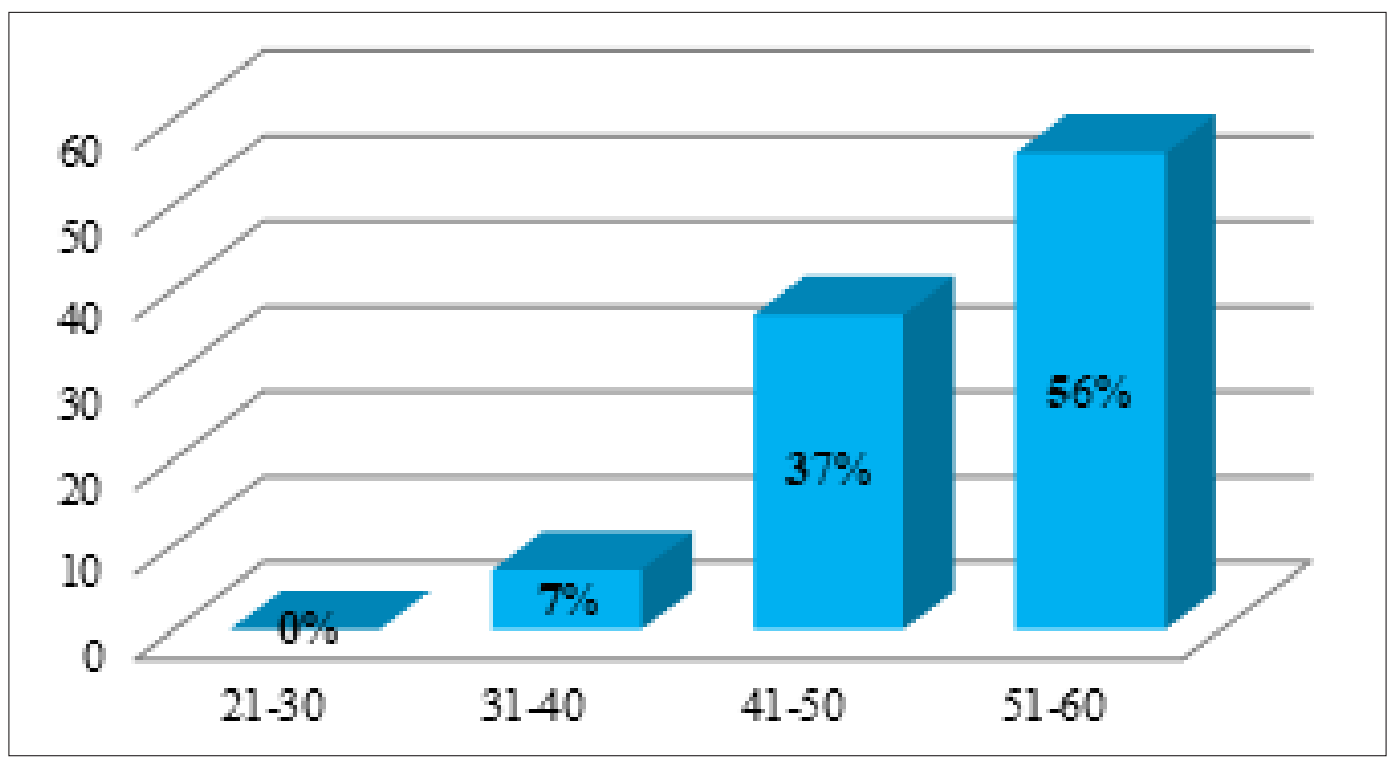

Figure 3.Distribution of worker according to hypertension in relation to age

Table 3A.Distribution of worker according to their BMI and Diabetes (DM)

\begin{tabular}{|c|c|c|c|c|}
\hline & \multicolumn{3}{|c|}{ No. of workers (n=140) } \\
\hline & \multicolumn{2}{|c|}{ DM } & \multicolumn{2}{c|}{ No DM } \\
\hline & No. & Percentage (\%) & No. & Percentage (\%) \\
\hline $18.5-24.9$ (Normal) & 06 & 30 & 68 & 57 \\
\hline $25.0-29.9$ (Overweight) & 11 & 55 & 47 & 39 \\
\hline$\geq 30$ (Obese) & 03 & 15 & 05 & 04 \\
\hline Total & $\mathbf{2 0}$ & $\mathbf{1 0 0}$ & $\mathbf{1 2 0}$ & 100 \\
\hline
\end{tabular}

Table 3B.Chi-square test (association between BMI and Diabetes)

\begin{tabular}{|c|c|c|c|}
\hline & DM & No DM & Row totals \\
\hline $\mathrm{BMI}>25$ & $14(9.43)[2.22]$ & $52(56.57)[0.37]$ & $\mathbf{7 4}$ \\
\hline $\mathrm{BMI}<25$ & $6(10.57)[1.98]$ & $68(63.43)[0.433]$ & $\mathbf{1 4 0}$ (Grand total) \\
\hline Column totals & 20 & 120 & \\
\hline
\end{tabular}




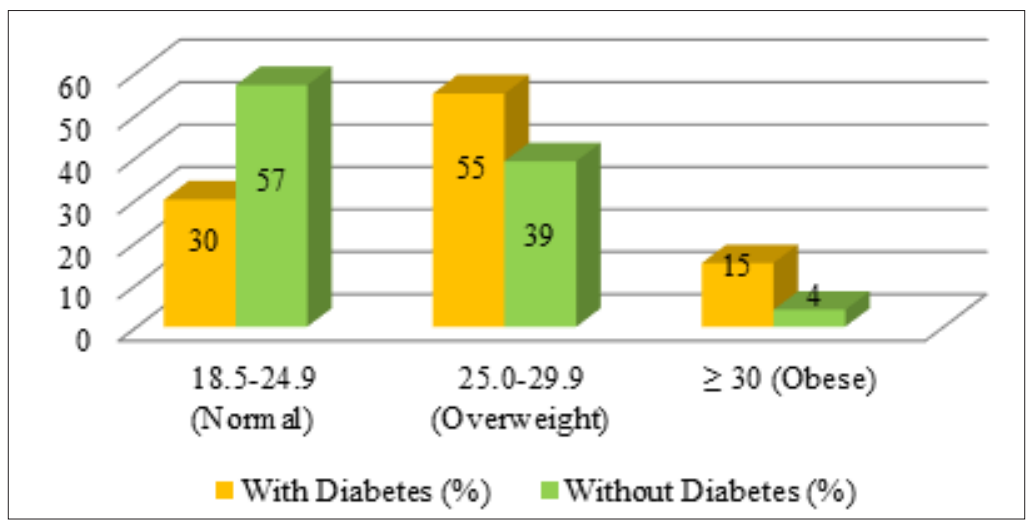

Figure 4.Comparison between BMI and Diabetes

Table 4A.Distribution of worker according to their BMI and hypertension

\begin{tabular}{|c|c|c|c|c|}
\hline \multirow{2}{*}{ BMI } & \multicolumn{4}{|c|}{ No. of workers (Total, $\mathrm{n}=140)$} \\
\hline & \multicolumn{2}{|c|}{ HTN } & \multicolumn{2}{c|}{ No HTN } \\
\hline & No. & Percentage (\%) & No. & Percentage (\%) \\
\hline $18.5-24.9$ (Normal) & 09 & 33 & 65 & 48 \\
\hline $25.0-29.9$ (Overweight) & 13 & 48 & 45 & 03 \\
\hline$\geq 30$ (Obese) & 05 & 19 & 113 & 100 \\
\hline Total & 27 & 100 & 02 \\
\hline
\end{tabular}

Table 4B.Chi-square test (association between BMI and hypertension)

\begin{tabular}{|c|c|c|c|}
\hline & HTN & No HTN & Row totals \\
\hline BMI $>25$ & $18(12.73)[2.18]$ & $48(53.27)[0.52]$ & 66 \\
\hline BMI $<25$ & $9(14.27)[1.95]$ & $65(59.73)[0.47]$ & 74 \\
\hline Column totals & 27 & 113 & 140 (Grand total) \\
\hline
\end{tabular}

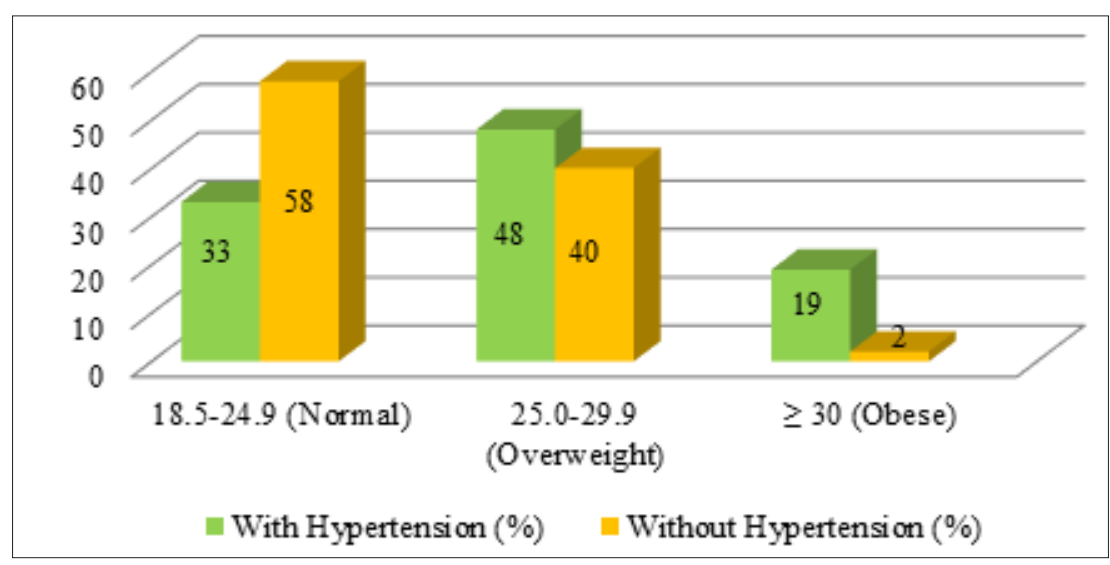

Figure 5.Comparison between BMI and Hypertension

Table 5A.Distribution of workers according to their Smoking habit and hypertension

\begin{tabular}{|c|c|c|c|c|c|}
\hline & \multicolumn{2}{|r|}{ HTN } & \multicolumn{2}{|c|}{ No HTN } & \multirow[t]{2}{*}{ Total } \\
\hline & No. & Percentage (\%) & No. & Percentage (\%) & \\
\hline Smoker & 17 & 63 & 40 & 35 & 57 \\
\hline Non-Smoker & 10 & 37 & 73 & 65 & 83 \\
\hline Total & 27 & 100 & 113 & 100 & 140 (Grand total) \\
\hline
\end{tabular}


Table 5B.Chi-square test (association between smoking and hypertension)

\begin{tabular}{|c|c|c|c|}
\hline & HTN & No HTN & Row totals \\
\hline Smoker & $17(10.99)[3.28]$ & $40(46.01)[0.78]$ & $\mathbf{5 7}$ \\
\hline Non-Smoker & $10(16.01)[2.25]$ & $73(66.99)[0.54]$ & $\mathbf{8 3}$ \\
\hline Column totals & $\mathbf{2 7}$ & $\mathbf{1 1 3}$ & $\mathbf{1 4 0}$ (Grand total) \\
\hline
\end{tabular}

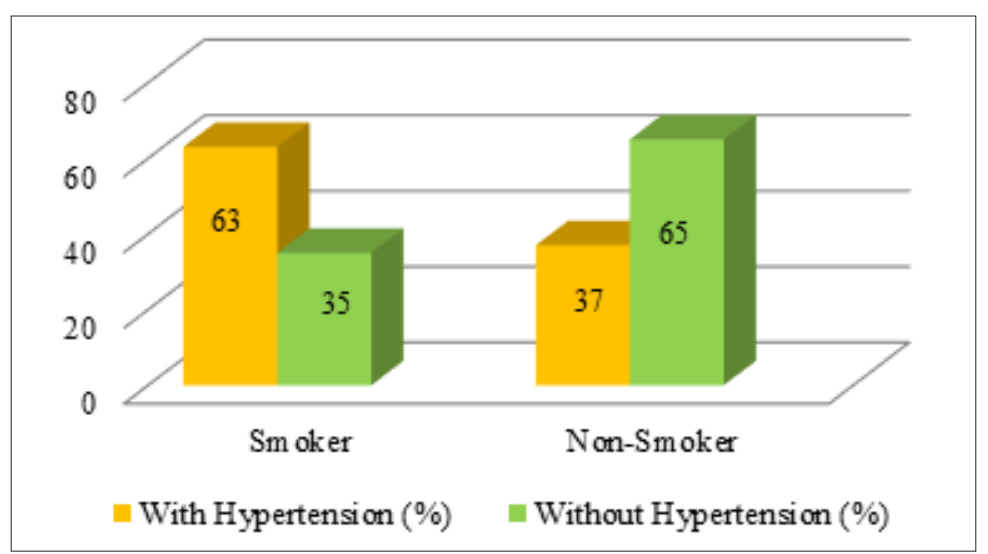

Figure 6.Association between smoking and hypertension

\section{Discussion}

Due to increased industrialization, socio-economic development, changing lifestyles, non-communicable diseases are posing major health problem in India as well as globally, mining workers are not the exception.

In the study population, $19 \%(n=27)$ were suffering from Hypertension. Among them, 56\% were in the age of $51-$ 60 years, and $37 \%$ and $7 \%$ were in the age of $41-50$ years and $31-40$ years respectively. It proves that hypertension is associated with advancement of age, which is a normal phenomenon. This finding was similar with the study by Mungreiphy NK et al. ${ }^{11}$ in India which showed Blood Pressure (both systolic and diastolic BP) increased with age steadily from the youngest to the oldest age group showing the dependence of BP on age. Similar findings of high blood pressure in relation to age were established in the study conducted by Bowman TS et al. ${ }^{12}$ in USA.

As per the study, $14 \%$ ( $n=20)$ were suffering from Diabetes, among them $55 \%$ were in age of $51-60$ years and rest of the population in below 50 years. So, the prevalence of diabetes steadily increases with advancement of age. This finding is quite similar with the study published in American Journal of Hypertension ${ }^{12}$ in 2006.

66 workers (47\%) had high BMI. Among them mostly in the age of $41-50$ years (39\%) followed by age of $51-60$ years (35\%) . So, most of the workers (74\%) with high BMI were above 40 years by age. Similar study ${ }^{11}$ in India revealed age was positively correlated with BMI.

Chi-Square test $\left(\mathrm{x}^{2}\right)$ was used for statistical analysis in the study and it was observed that BMI was significantly associated (at $p<0.05)$ with diabetes $\left(x^{2}=4.8922, d f=1\right.$, $p=0.026979)$ and hypertension $\left(x^{2}=5.1171, d f=1\right.$, $p=0.023691$ ). Table 3A-3B, 4A-4B and Figure 4 and 5 showed the analysis among the workers according to diabetes (DM) and hypertension respectively. Similar study ${ }^{13}$ at New Delhi, India, among the Punjabi populations showed significant positive correlation between BMI, fat percentage and both-systolic and diastolic blood pressure. Studies outside India also established high BMI as a contributory factor for hypertension. ${ }^{14,15}$

The present study found that those suffering from hypertension tend to be older, as well as overweight or obese. A higher prevalence of hypertension in older adults is generally known, as well as the higher prevalence of hypertension among those with $\mathrm{BMI}>25$ (overweight or obese). It has been described, that overweight or obese patients suffer more often by chronic medical disorders. ${ }^{16}$

Smoking also showed statistically significant association $\left(x^{2}=6.86, d f=1, p=0.008815\right.$, at $\left.p<0.05\right)$ with hypertension (Table 5A-5B and Figure 6). Similar findings of high blood pressure among the smokers were established in the study conducted by Halperin RO et al. ${ }^{17}$ in USA in American Journal of Hypertension in 2008.

\section{Conclusions}

From the data analysed, it has been found that noncommunicable diseases (NCD) are important issue in today's working environment and NCDs are supposed to be major health problem in India, as well as globally in coming days. NCDs are also major problem for mining workers.

Like all occupational diseases, prevention takes the 
major role for NCDs.With more restricted life, life-style modifications, following good habits and healthy food habits NCDs can be prevented.

Although WHO warned in different occasions in different forum about the topic and different studies are going on but Global concerns and effort by ILO/WHO is required to encourage formulation of national program and strategies for prevention of NCDs. Detailed studies should be conducted in future on the same topic, in a large sample with long duration by the Govt. / large private organizations/ in joint venture for more analytical data and specific result. More research works to be needed.

\section{General Recommendations}

- Workers must be aware of hazards present in workplace.

- To identify all "High Risk" cases and awareness in personal level, strict follow up of all the workers suffering from non-communicable diseases.

- More emphasis on Pre-employment and Periodical medical examination (PME) of workers to detect the non-communicable diseases in early stages.

- Motivate them to do Physical exercise, Yoga regularly to keep them fit \& for stress management.

\section{Specific Recommendations}

- Weight management plan by regular follow-up of the workers who are overweight or obese and prepare "Diet Chart" for them.

- Hypertension and Diabetes control plan by regular follow up for persons suffering from those chronic ailments and advise them for lifestyle modifications and other valuable suggestions. If not controlled, advise them to take regular medicines.

- De-addiction program, Smoking- cessation program on regular basis. "One to one" counselling and advice to give up their personal habits like smoking, alcoholism etc.

- More Awareness sessions / shop floor classes/training program on NCDs / Life-style related diseases.

\section{Conflict of Interest: None}

\section{References}

1. Park K. Park's Textbook of Preventive and Social Medicine, 21 $1^{\text {st }}$ Ed. 2011.

2. Agarwal D, Shukla M, Garg A. A cross-sectional study on non-communicable diseases risk factors in a rural population of Barabanki District, Uttar Pradesh. Annals of Community Health 2017; 1(5): 5-8.

3. Manjunath KS. Health Profile of Employees working in automobile industry in Shirur, India - A cross-sectional study. Int J Curr Res Aca Rev 2015; 3(7).

4. Magdalena RZ, Dandona R, Dandona L. Availability of data for monitoring noncommunicable disease risk factors in India. Bulletin of the World Health Organization 2012; 90: 20-9.

5. Pravin et.al. A study on risk factor profile of hypertension and diabetes among industrial workers of South India. Innovative Journal of Medical and Health Science 2015; 5: 31-3.

6. Divya Z, Tripathy BK. Handling non-communicable disease using predictive analysis of data mining techniques. Helix 2017; 7(5): 2034-40.

7. Giri RC. Impact of mining on health of workers at Samaleswari OCP, Brajarajnagar. Project report on Mahanadi Coalfields Ltd.

8. Definition and diagnosis of diabetes mellitus and intermediate hyperglycaemia. World Health Organization. Available from: http://apps.who.int/iris/ bitstream/handle/10665/43588/9241594934_eng. pdf;jsessionid=CEA24D3A41B617BF49C5E79783E7A5EF? sequence $=1$.

9. Reference Card from Seventh Report of the Joint National Committee on Prevention, Detection, evaluation and treatment of high blood pressure (JNC 7). Available from: https://www.nhlbi.nih.gov/files/https:www. nhlbi.nih.gov/files/docs/resources/heart/phycard.pdf.

10. Global Database on Body Mass Index an interactive surveillance tool for monitoring nutrition transition. World Health Organization. Available from: http:// apps.who.int/bmi/index.jsp?introPage=intro_3.html.

11. Mungreiphy NK. Association between BMI, blood pressure, and age: study among Tangkhul Naga tribal males of northeast India. Journal of Anthropology 2011; Article ID 748147, 6 pages.

12. Bowman TS, Sesso HD, Gaziano JM. Effect of age on blood pressure parameters and risk of cardiovascular death in men. American Journal of Hypertension 2006; 19: 47-52.

13. Dua $S$, Bhuker $M$, Sharma $P$, et al. Body mass index relates to blood pressure among adults. North American Journal of Medical Sciences 2014; 6: 89-95.

14. Abdalla MS. Correlation between body mass index and blood pressure. International Journal of Scientific and Research Publication 2017; 7(10).

15. Eshkoor SA, Hamid TA, Shahar S, et al, Factors affecting hypertension among the malaysian elderly. J Cardiovasc Dev Dis 2016; 3(1): 8.

16. Kearns K, Dee A, Fitzgerald AP, Doherty E, Perry IJ. Chronic disease burden associated with overweight and obesity in Ireland: the effects of a small BMI reduction at population level. BMC Public Health. 2014; 14: 143.

17. Halperin RO, Gaziano JM, Sesso HD. Smoking and the risk of incident hypertension in middle-aged and older men. Am J Hypertens 2008; 21(2): 148-52.

Date of Submission: 2018-06-22 Date of Acceptance: 2018-06-30 